\section{(1)}

CrossMark

\title{
The adipose tissue and lung health: like many things in life, the extremes are not good
}

\author{
Miguel J. Divo (1) \\ Affiliation: Pulmonary and Critical Care Division, Brigham and Women's Hospital, Harvard Medical School, \\ Boston, MA, USA. \\ Correspondence: Miguel J. Divo, 75 Francis Street, Pulmonary and Critical Care Division, Brigham and \\ Women's Hospital and Spaulding Rehabilitation Hospital, Boston, Massachusetts 02115 USA. E-mail: mdivola
} bwh.harvard.edu

@ERSpublications

Adipose tissue is not an inert organ but rather a systemic modulator of the response to environmental exposures and perhaps a potential target for therapeutic intervention https://bit.ly/2UPRqqd

Cite this article as: Divo MJ. The adipose tissue and lung health: like many things in life, the extremes are not good. Eur Respir J 2020; 55: 2000107 [https://doi.org/10.1183/13993003.00107-2020].

Most epidemiological population studies in COPD have historically being conducted in North America and Europe. This hegemony was held until the PLATINO [1] and BOLD [2] studies broke the monopoly. Among the many contributions made by these population-based studies are the description of underrepresented populations, the increased relevance given to the never-smoker COPD phenotype, and the race-specific risks for developing or resisting the disease. In spite of these advances, populations from the middle and far East and African countries continue to be underrepresented in the literature.

Health is an undeniable universal human right and we most incorporate broad racial, gender, community and regional diversity to our health know-how, if we want to pursue a more "personalised medicine" path. Asia is the most populous continent, accounting for $60 \%$ of the world population and for the largest absolute number of cases of COPD (figure 1), yet the problem is clearly understudied. Moreover, Asia encompasses a conglomerate of nations with cultural, historical, economic, environmental and genetic differences. Replicating or exploring new hypothesis in these regions is therefore a necessity.

In this issue of the European Respiratory Journal, Li et al. [3] describe the incidence risk of hospitalisation or death of subjects with a diagnosis of COPD and the interaction with adiposity in an adult Chinese cohort. In this observational study they included almost 500000 subjects from diverse regions of China followed for an average of 10 years. They evaluated how generalised adiposity, expressed by the body mass index (BMI), and abdominal adiposity, expressed as waist circumference, influences the incidence of COPD hospitalisations or death. Over the period of observation, they captured 10739 hospitalisations or deaths where the ICD-10 J41-J44 (simple and mucopurulent chronic bronchitis, unspecified chronic bronchitis, emphysema, other chronic obstructive pulmonary disease) were coded.

They found that underweight subjects $\left(\mathrm{BMI}<18.5 \mathrm{~kg} \cdot \mathrm{m}^{-2}\right.$ ) had a $78 \%$ increased risk of developing either of the above events compared to subjects with a BMI of $23-25 \mathrm{~kg} \cdot \mathrm{m}^{-2}$. In addition, after adjusting for BMI, a higher waist circumference $(\geqslant 85 \mathrm{~cm}$ for men and $\geqslant 80 \mathrm{~cm}$ for women) were also associated with the same outcomes. They concluded that abdominal adiposity and underweight are risk factors for COPD in Chinese adults. 


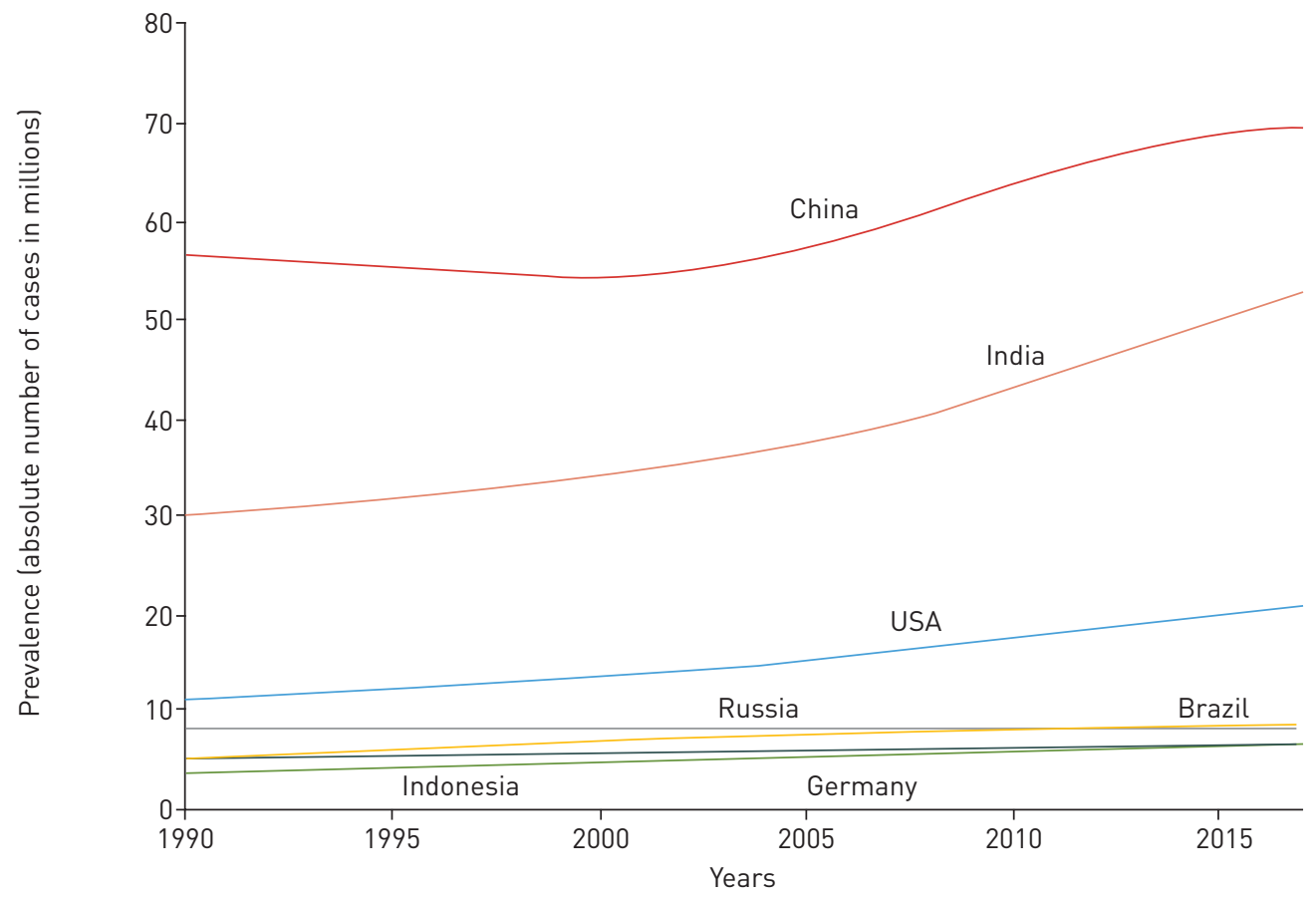

FIGURE 1 Absolute prevalence of COPD in seven of the most populous countries in the world. From Global Burden of Disease Collaborative Network. Global Burden of Disease Study 2017 Results, Seattle, Institute for Health Metrics and Evaluation (IHME), 2018. Available from http://ghdx.healthdata.org/gbd-results-tool

The study strengths are the absolute number of Chinese adults enrolled (half a million recruited over 4 years), with an urban and rural representation and with a large proportion of females (60\%). In addition, the thorough statistical analysis that included different regression models with corrections for confounders, interaction terms, and sensitivity analysis to shield their findings from potential bias. However, the benefits of having a large number of subjects with enough power to test many hypotheses is frequently coupled, as is it is here, with a lower granularity, as is noted with the outcome ascertainment in this study. At baseline, the enrolled subjects underwent an extensive characterisation that included spirometry, anthropometric measurements, nutrition and behavioural risk questionnaires, while for the outcome, they only included those individuals who were hospitalised or died with a diagnosis of COPD based on identification of the ICD-10 code J41-J44 in their hospital records. This means that the reported incidence rate was very likely influenced by mis-, under- or over-diagnosis, as participants did not have a follow up spirometry to confirm the diagnosis of COPD [4].

Nevertheless, if we assume that ascertainment bias can be diluted by the large number of participants, then the 10739 participants in which the diagnosis of COPD was assigned, are worth being followed and studied further (with spirometry and body composition!). These participants who either were hospitalised or died during the follow-up period comprised individuals between the ages of 30 and 79 years, of whom $28 \%$ were smokers and $37 \%$ were exposed to biomass fuel with a normal spirometry at baseline. After an average of 10 years, they developed a complication assigned to a COPD ICD-10 diagnosis. Based on what we know about lung function trajectories, in order to reach a clinical phase of COPD severe enough to lead to hospitalisation or death, this group with a normal spirometry at baseline had to comprise subjects with accelerated (>50 mL per year) loss of lung function or severe comorbidities associated with COPD [5-8].

How can we then tie such an accelerated loss of lung function with adiposity, or the lack thereof? In the discussion the authors suggest the too simple presence of persistent inflammation as the potential mechanism. However, persistent inflammation is seen in the obese, but not necessarily in the underweight COPD patient [9]. Therefore, to account for the findings reported in the study, more than one mechanism should be entertained. Indeed, those subjects with a lower BMI most likely represent the predominantly emphysematous multi-organ loss of tissue (MOLT) phenotype, characterised by loss of tissue of mesenchymal origin [10], due to a shortage of adipose-derived-stromal cells, capable to differentiate into bone, muscle or connective tissue [11]. For the higher BMI subjects with central obesity, chronic bronchitis is likely the predominant phenotype [12] and persistent chronic inflammation mediated by adipokines may be the best explanation for the observed findings [13]. Taken together, the evidence 
supports the concept that the adipose tissue is not an inert organ but rather a systemic modulator of the response to environmental exposures and a potential target for novel therapeutic intervention.

Conflict of interest: M.J. Divo has nothing to disclose.

\section{References}

1 Menezes AMB, Perez-Padilla R, Jardim JB, et al. Chronic obstructive pulmonary disease in five Latin American cities (the PLATINO study): a prevalence study. The Lancet 2005; 366: 1875-1881.

2 Buist AS, McBurnie MA, Vollmer WM, et al. International variation in the prevalence of COPD (the BOLD Study): a population-based prevalence study. Lancet 2007; 370: 741-750.

3 Li J, Zhu L, Wei Y, et al. Association between adiposity measures and COPD risk in Chinese adults. Eur Respir J 2020; 55: 1901899

4 Singh D, Agustí A, Anzueto A, et al. Global Strategy for the Diagnosis, Management, and Prevention of Chronic Obstructive Lung Disease: the GOLD science committee report 2019. Eur Respir J 2019; 53: 1900164.

5 Lange P, Celli B, Agusti A, et al. Lung-function trajectories leading to chronic obstructive pulmonary disease. N Engl J Med 2015; 373: 111-122.

6 Divo MJ, Celli BR, Poblador-Plou B, et al. Chronic obstructive pulmonary disease (COPD) as a disease of early aging: evidence from the EpiChron Cohort. PLoS One 2018; 13: e0193143.

7 Divo MJ, Cabrera C, Casanova C, et al. Comorbidity distribution, clinical expression and survival in COPD patients with different body mass index. Chronic Obstr Pulm Dis 2014; 1: 229-238.

8 Divo MJ, Cote C, de Torres JP, et al. Comorbidities and risk of mortality in patients with chronic obstructive pulmonary disease. Am J Respir Crit Care Med 2012; 186: 155-161.

9 Agustí A, Edwards LD, Rennard SI, et al. Persistent systemic inflammation is associated with poor clinical outcomes in COPD: a novel phenotype. PLoS One 2012; 7: e37483.

10 Celli BR, Locantore N, Tal-Singer R, et al. Emphysema and extrapulmonary tissue loss in COPD: a multi-organ loss of tissue phenotype. Eur Respir J 2018; 51: 1702146.

11 Bonfield TL, Caplan AI. Adult mesenchymal stem cells: an innovative therapeutic for lung diseases. Discov Med 2010; 9: 337-345.

12 Rennard SI, Locantore N, Delafont B, et al. Identification of five chronic obstructive pulmonary disease subgroups with different prognoses in the ECLIPSE cohort using cluster analysis. Ann Am Thorac Soc 2015; 12: 303-312.

13 Agustí A, Barberà JA, Wouters EFM, et al. Lungs, bone marrow, and adipose tissue. A network approach to the pathobiology of chronic obstructive pulmonary disease. Am J Respir Crit Care Med 2013; 188: 1396-1406. 